\title{
ПРОБЛЕМЫ И ПЕРСПЕКТИВЫ РАЗВИТИЯ НЕФТЕГАЗОВОГО КОМПЛЕКСА НИГЕРИИ
}

(c) 2021 Козеняшева Маргарита Михайловна

доктор экономических наук, профессор, заведующая кафедрой «Международного нефтегазового бизнеса» РГУ нефти и газа (НИУ) имени И. М. Губкина, Россия, Москва

E-mail: MKozenyasheva@gmail.com

\section{(c) 2021 Гвана Фвангмун Бесан}

аспирант кафедры «Международного нефтегазового бизнеса» РГУ нефти и газа (НИУ) имени И. М. Губкина, Россия, Москва

E-mail: gwana983@gmail.com

В статье рассмотрены сложность проблемы интеграции Нигерии в современной мировой экономической системе и перспективы развития нефтегазового комплекса Нигерии. Отдельный акцент сделан на иностранных инвесторов, активно распространяющих своё участие в нефтяном секторе. Кроме того, нефтяной сектор Нигерии продолжает развиваться в непростых условиях и новым перспективным направлением его развития становится морская нефтегазодобыча. Также обозначены НПЗ Данготе и, как ожидается в ближайшие годы, страна будет являться региональным перерабатывающим центром.

Ключевые слова: Нигерия, экономика, импорт, нефтепереработки, добыча, инвестиции, экспорт.

Введение. Прошедшие десятилетия показали, что одной из ключевых основ развития как мировой экономики в целом, так и каждой страны в частности является стабильное обеспечение энергоносителями. В XXI в. условия развития мировой энергетики характеризуются переходом к вовлечению в эксплуатацию трудноизвлекаемых ресурсов, прежде всего нефти и природного газа, противоречиями между наличием собственных энергоносителей стран и потребностью в них, значительным загрязнением окружающей среды вследствие их добычи и переработки, резким повышением спроса на энергоресурсы, обусловленным ростом населения планеты и промышленным ростом, прежде всего, в странах Юго-восточной Азии.

Синергическое действие комплекса этих факторов обусловливает современные тенденции обострения энергетических вопросов мировой экономики и каждой отдельной страны. Необходимость обеспечения энергетических потребностей развития собственной экономики ведет к усилению борьбы между странами за обладание ресурсами, за их транспортировку и влияние на рынок энергоносителей. При этом к этой борьбе пытаются присоединиться все экономики мира без исключения. Глобализация мировой энергетики ведет к тому, ряд стран получают неоспоримые преимущества в обеспечении собственного экономического роста, и оказания влияния на экономическое развитие других стран. Те страны, которые оказываются на задворках мировых энергетических процессов, попадают под угрозу потери собственной энергетической независимости, которая, в свою очередь, является одним из факторов национальной безопасности.

Федеративная республика Нигерия, обладая огромным энергетическим потенциалом, сегодня продолжает играть роль лидера в западноафриканских регионе, и все более претендует на лидерство в рамках всего континента.

Стратегия нигерийской внешней политики нацелена на расширение международных торговых связей, в том числе и в энергетике. Ведущая роль отводится экономической дипломатии, политика которой направлена на привлечение внешней помощи, иностранных инвестиций, ослабление долгового бремени.

Сложность проблемы интеграции Нигерии в современную мировую экономическую систему заключается в том, что необходимо создать условия относительной свободы международной экономической деятельности на территории страны при регулирующей роли государства.

Развитие рынка энергоносителей Нигерии 
требует исследования многих аспектов этой проблематики, которые в настоящее время все еще недостаточно разработаны в научной литературе. Отметим, что отдельным вопросам развития экономики Нигерии е ее нефтегазового комплекса были посвящены работы таких российских и зарубежных исследователей как Ф.Е.Абилогун, М.Баркиндо, Дж.Гаиус-Обасеки, Ф.Б.Гвана， Э.Р.Гималетдинова， О.Р.Екпободо, Г.Г. Карачурина, Р.Лукман, К.Нвизуг-Би Лейи, Э. Отори О.В. Савенок и др. [1;2;3]

Во многих исследованиях, в том числе и в указанных выше, было отмечено, что в течение длительного колониального периода структура экономики Нигерии формировалась под влиянием английского капитала. Страна была приспособлена к потребностям мирового рынка: осваивались виды природных ресурсов и те территории, которые были связанные с развитием экспорта какао, хлопка, пальмового масла и ореха, каучука и др. сырья. Нигерия обрела независимость от Великобритании, чье господство длилось годами, в 1960 году. С 1971 г. Нигерия является членом ОПЕК и в том же году была создана Нигерийская национальная нефтедобывающая компания (NNPC).

B настоящее время страна занимает седьмое место по экспорту нефти в мире. Как член Организации стран-экспортеров нефти (ОПЕК), Нигерия подтвердила свое обязательство по сокращению добычи сырой нефти в апреле 2020 года, установив предел добычи на уровне 1,41 миллиона баррелей в день (баррелей в день). Соглашение вступило в силу 1 мая 2020 г. и заканчивается 30 апреля 2022 г. Однако соблюдение Нигерией соглашения ОПЕК+ было прерывистым; в прошлом страна порой производила больше, чем согласованная квота.

Кроме того, Нигерия определила некоторые из своих потоков сырой нефти как «арендный конденсат», на который не распространяется действие соглашения ОПЕК+ о сокращении добычи, что позволяет Нигерии обойти свое обязательство по сокращению добычи.

В 80-х гг. XX в. правительством была принята новая стратегия экономического развития, программа которой была направлена на добычу нефти, руды и угля, в том числе и продажу этого сырья на мировом рынке. Доля сельского хозяйства, которая в начале 70-х гг. составляла в общем объеме валового национального продукта (ВНП) 40\%, упала в 1980 гг. до 20\%, а доля неф- ти в общем объеме ВНП возросла с $22 \%$ до $34 \%$ и составила в 2010 г. 99\% экспортных поставок страны.

Согласно этой стратегии, Нигерия в короткие сроки подняла уровень рентабельности отдельных отраслей тяжелой промышленности, сократила импорт в страну, установила национальный контроль над ключевыми отраслями и сферами хозяйства, а также обеспечила ведущую роль государственного сектора в экономическом развитии и частично в других отраслях. Далее, правительством был проведен ряд важных экономических мер, в результате которых расширилась долевое участие государства в активах иностранных компаний.

Однако низкий уровень научно-технического развития большинства отраслей Нигерии до сих пор обусловливает необходимость импортировать высокотехнологичные товары, такие как машины, оборудование, транспортные средства и химические вещества, изделия электротехнической, легкой промышленности, которые не производятся в стране. Также в результате быстрого роста населения Нигерии усилилась необходимость импортировать продукты питания, напитки и табачные изделия для того, чтобы удовлетворять внутренние потребности.

В настоящее время Нигерия торгует более, чем со 100 странами. Основным торговым партнером Нигерии является Китай, торговля с ним составляет примерно $25 \%$ всей внешней торговли Нигерии. Другими крупными торговыми партнерами являются США, Индия, Бразилия, Нидерланды, ЮАР, Бельгия и Испания [4]. Роль международной торговли Нигерии в мировой экономике невелика из-за низкого уровня экспорта и импорта по сравнению с другими странами мира с развитой рыночной экономикой.

Что касается экспорта сырой нефти, то главными направлениями поставок выступают страны Западная Европа- 47\%, затем Юго-Восточная Азия. Около 10\% всех экспортных отгрузок нефти из Нигерии поступает на рынки стран Африки (рис.1).

Основная часть. Сегодня большинство нефтедобывающих компаний Нигерии - это совместные предприятия Национальной нефтедобывающей компании Нигерии (NNPC) с такими нефтяными гигантами как, Shell / NNPC, Chevron / NNPC, Mobil / NNPC, Agip / NNPC, Elf / NNPC, Tехасо / NNPC и др. Последние осуществляют 


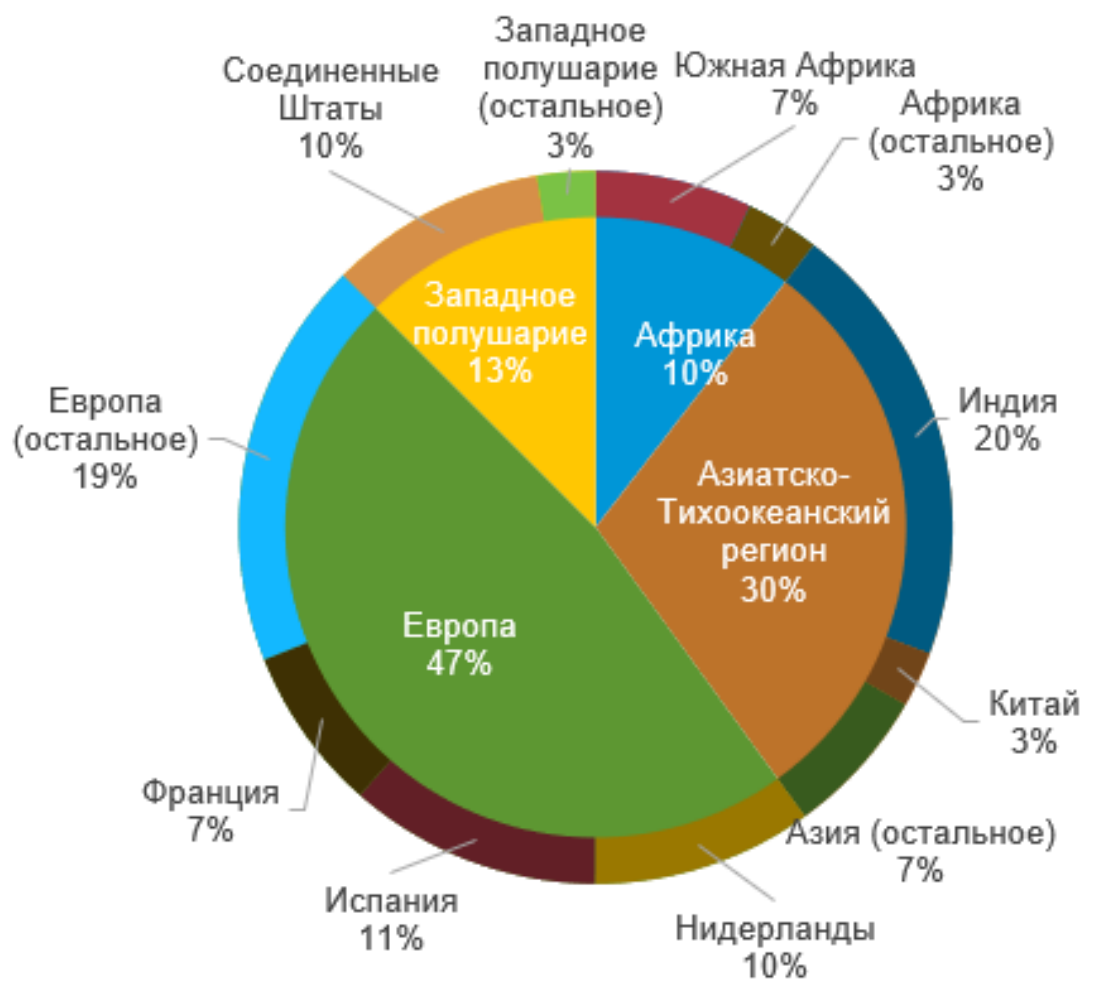

Puc. 1. Основные направления экспорта сырой нефти и газоконденсата из Нигерии, 2019 г. (\%). Источник: https://www.eia.gov/international/analysis/country/NGA

свою деятельность в соответствии с Соглашениями о разделе продукции (СРП), новые условия которых были приняты в стране в 1994 году. На сегодняшний день правительство финансирует $60 \%$ всех операций по добыче и имеет такую же долю в добытой прибыльной нефти.

Общий годовой объем производства, потребления и экспорта жидкого топлива в Нигерии, приведен на рис. 2.

Реализуя в стране соглашения по разделу продукции, Правительство Нигерии учитывает возможности государственного регулирования. В стране существуют правовые и законодательные условия, в рамках которых осуществляются все подобные сделки. Правовые и договорные условия сделок с международными нефтедобывающими компаниями являются основой для расширения объема привлекаемых иностранных инвестиций и совершенствования организационных форм нефтяного бизнеса в государстве.

Однако возможности дальнейшего привлечения инвестиций столкнулись с ограничениями, вызванными пандемией. Так, в 2020 г. помимо воздействия COVID-19 на экономику страны, производители нефти столкнулись с падением не только цен, но и спроса на нефть, что привело к ее перенасыщению рынка.

В своем отраслевом циркуляре от 30 марта 2020 года Департамент нефтяных ресурсов (DPR) заявил, что считает ситуацию, вызванную пандемией COVID-19, форс-мажором, и дал указание всем операторам ограничить количество персонала на объектах проекта, хотя это могло вести к нарушению определенных условий контрактов [5]. Одним из основных факторов, влияющих развитие нефтяного рынка, является увеличение инвестиций в сектор разведки и добычи, развитие крупных и модульных нефтеперерабатывающих заводов в стране, однако нестабильная внутриполитическая обстановка также не способствует расширению иностранных инвестиций в сектор. Отметим, что в последние несколько лет добыча нефти и газа в Нигерии была затруднена из-за нападения боевиков на нефтегазовую инфраструктуру. Кроме того, хищение нефти было одной из основных проблем, с которыми сталкивается рынок нефти и газа в Нигерии, что привело к огромным убыткам для компаний - операторов, работающих в стране. Можно предположить, что такие факторы будут и в будущем оказывать негативное влияние на рост внутреннего рынка.

Однако нефтяной сектор Нигерии продолжа- 


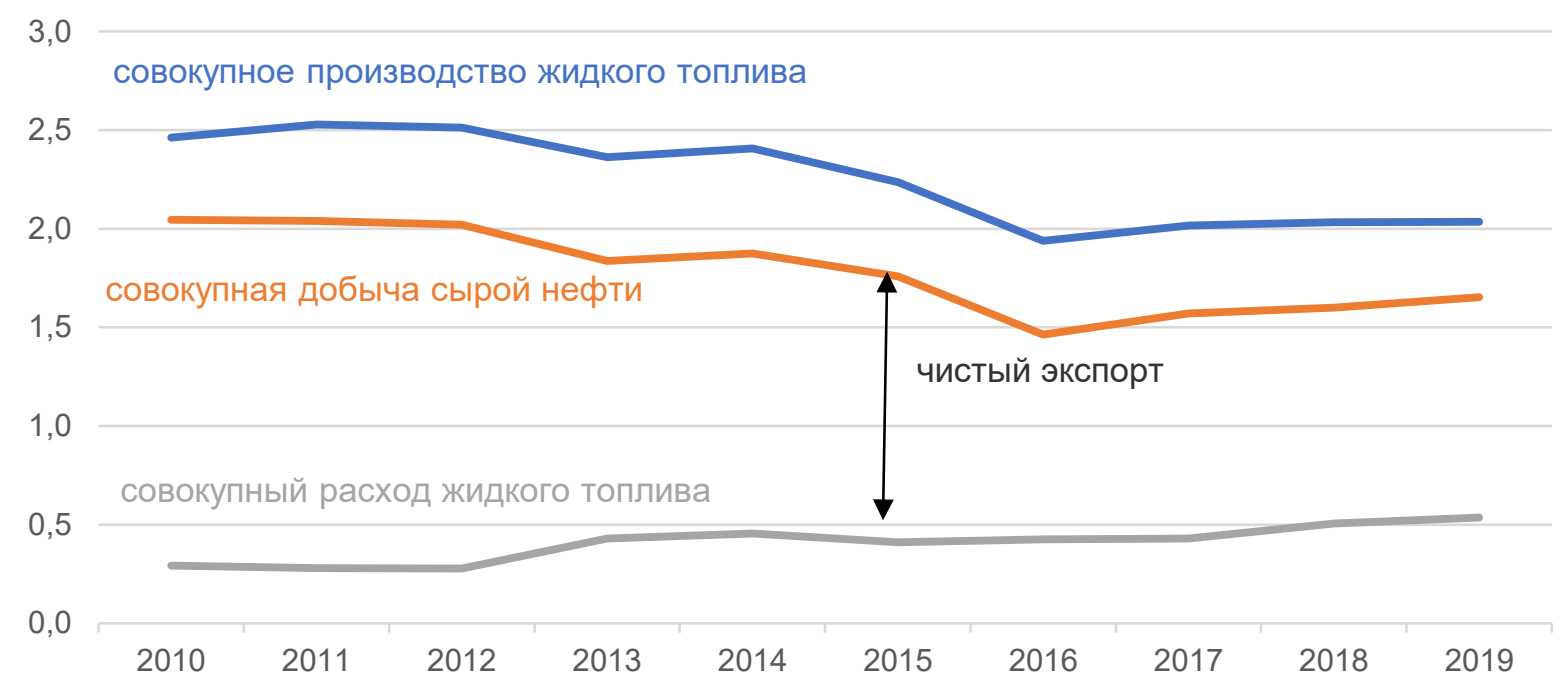

Puc. 2. Динамика добычи, потребления и экспорта нефти в Нигерии 2010-2019 гг. (млн. барр/с). Источник: https://www.eia.gov/international/analysis/country/NGA

ет развиваться в непростых условиях и новым перспективным направлением развития становится морская нефтегазодобыча. Рост объемов разведки и добычи на шельфе Нигерии был обеспечен в основном усилиями правительства по развитию углеводородной составляющей экономики страны.

Расширение внутреннего рынка сдерживается и такими факторами как отсутствие инфраструктуры, нерешенность проблем безопасности и это привело к тому, что Нигерия не смогла эффективно использовать свои перерабатывающие мощности, тем самым подтолкнув страну к ее превращению в нетто-импортера нефтепродуктов. Однако медное продвижение в сторону топливного самообеспечения все же происходит, и Нигерия стоит на пороге изменения динамики предложения нефтепродуктов не только с целью покрытия собственных, но и региональных потребностей с помощью строящегося в настоящее время НПЗ в Данготе и, как ожидается, в ближайшие годы страна станет региональным перерабатывающим центром [6]. После завершения строительства и наращивания перерабатывающих мощностей Нигерия планирует стать центром нефтепереработки в Африке. Ожидается, что такой подход в ближайшем будущем будет способствовать привлечению иностранных игроков в этот сектор ТЭК.

Однако для достижения поставленных целей необходимо решить целый комплекс проблем: в первую очередь необходимо добиться снижения издержек производства в отрасли, которые в стране достаточно велики, включая: расходы на персонал, затраты на логистику, затраты на добычу нефти и ее переработку и прочие. Правительство ставит задачу довести себестоимость добычи нефти до 10 долларов за баррель.

Ожидается, что в течение планируемого периода 2021-2026 гг., рынок нефти и газа Нигерии будет расти со среднегодовым темпом более $2 \%$, однако, по мнению экспертов, операционные расходы Нигерии в 2019 году были одни из самых высоких, а цена безубыточности для крупных предложенных проектов колебалась на уровне 48 долларов за баррель, что выше 45 долларов в Анголе и 44 доллара за баррель в Уганде.

Поскольку Правительство делает ставку на увеличение доходов от нефтегазового сектора страны, то для решения этого комплекса проблем был предложен инновационный подход. В стране создан Национальный центр передового опыта в нефтегазовой отрасли (NOGEC), работающей под контролем Департамента нефтяных ресурсов (DPR). Предусмотрено, что центр будет служить интегрированным ресурсным комплексом для внедрения рентабельных решений в отрасли с учетом факторов неопределенности на мировом рынке сырой нефти, когда добывающие нефть по самой низкой цене производители смогут остаться на рынке, в то время как компании, имеющие высокую себестоимость добычи, не смогут остаться по причине неконкурентных цен.

До недавнего времени поисково-разведочные работы в Нигерии были ориентированы на нефть, однако страна располагает значительными запасами газа. В настоящее время в Нигерии 
известно 25 месторождений газа. Большинство запасов - это газ в газовых шапках нефтяных месторождений (около 70\%), и газ, растворенный в нефти [7].

Учитывая запасы газа в стране и его преимущество в качестве чистого топлива, в последние годы сделана ставка на значительное увеличение внутреннего потребления газа. Кроме того, Нигерия изучает различные способы замены потребления нефти газом в энергетике, а также в транспортном секторе.

Расширятся экспорт СПГ из страны. Объемы импортных поставок сжиженного природного газа в ЕС в I квартале 2020 г. демонстрировали рост - на $26 \%$ по сравнению с соответствующим периодом предыдущего года. В настоящее время конкуренция на европейском рынке СПГ усиливается. Так, в I квартале 2020 г. США остались одним из ведущих поставщиков СПГ в страны $\mathrm{EC}$, обеспечив $30 \%$ от общего импорта СПГ, однако по итогам 2020 г. Россия впервые сумела поставить в Европу больший объем СПГ, чем компании США*. Впервые за последние пять лет Катар стал лишь третьим источником поставок LNG в EC с долей 15\%, а Нигерия с долей $13 \%$ заняла четвертую позицию [8].

В 2020 г. рынки газа пострадали от потрясений спроса, вызванных пандемией Covid-19, а восстановление экономики после отмены мероприятий блокировки было медленным. Предварительные данные свидетельствуют о том, что потребление газа в мире сократилось на рекорд- ные 4\%, причем сокращение произошло в большинстве регионов, импортирующих газ. Ожидается, что мировой спрос на газ будет постепенно восстанавливаться в 2021 году, но пандемия будет оказывать долговременное влияние на газовые рынки, поскольку формирует фактор неопределенности в среднесрочной перспективе.

Переход на газ также поддерживается тем, что рынок нефти считается одним из наиболее уязвимых рынков, на который природный газ имеет наибольший потенциал для проникновения на рынок (рис. 3). Более того, добыча газа стала основным направлением деятельности нефтегазовых компаний в связи с активными инвестициями в проекты по производству электроэнергии из газа в городах Коги, Нигер, Кадуна и Абуджа [9].

Среди законов, нацеленных на улучшение условий для привлечения инвестиций в нефтегазовый сектор экономики Нигерии, необходимо выделить те, что связаны с реформой структурной перестройки и либерализации для обеспечения большей открытости и поддержки процесса приватизации. На сегодняшний день значительное количество предприятий в стране находится в государственной собственности, однако здесь активно воплощается программа приватизации.

Ключевые изменения в регулировании условий для прямых иностранных инвестиций (ПИИ) в Нигерии касаются доли владения бизнесом иностранными инвесторами, вопросов экспро-

\footnotetext{
*https://tass.ru/ekonomika/10813365.
}

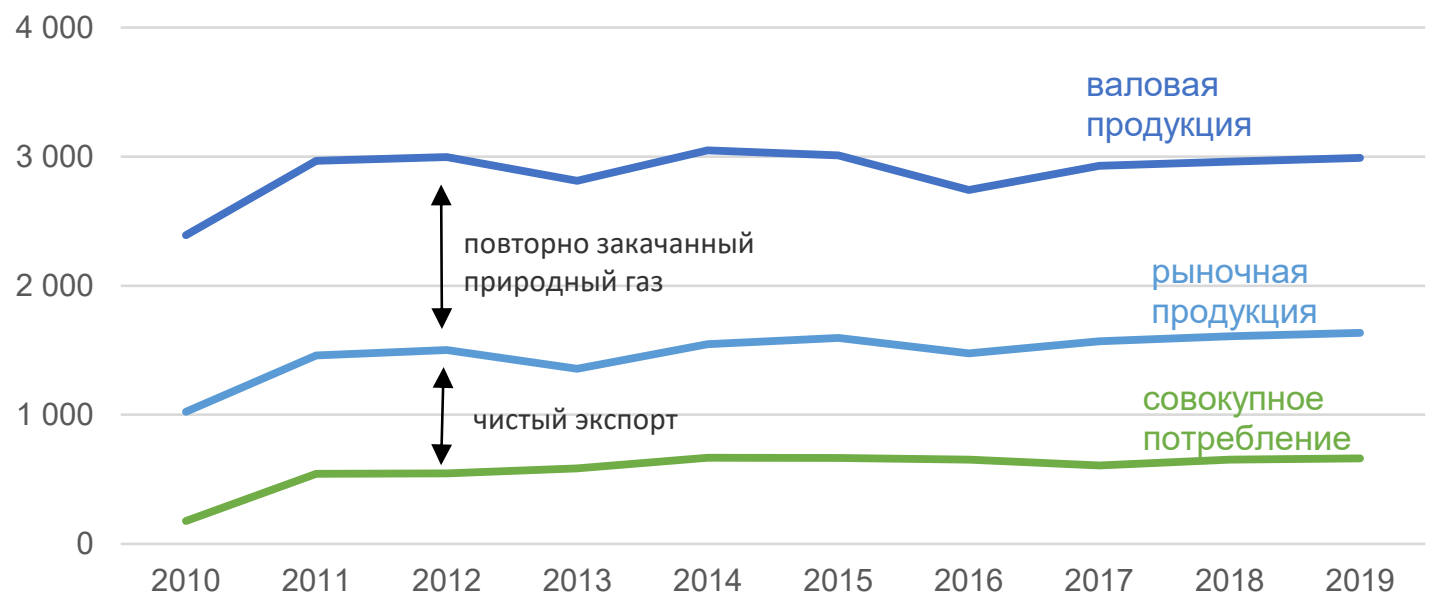

Puc. 3. Годовая добыча и потребление природного газа в Нигерии, млрд. футов куб. Источник: https://www.eia.gov/international/analysis/country/NGA. 
приации и компенсаций, урегулирования споров, прозрачности, защиты прав собственности, а также контроля за обменным валютным курсом.

Нигерия присоединилась к международным институтам, которые регулируют экономическое сотрудничество с иностранными инвесторами. К ним относятся Международный центр по урегулированию инвестиционных споров (МЦУИС), членами которого являются все страны Западной Африки, кроме Кабо-Верде; Агентство по многостороннему гарантированию инвестиций Всемирного банка, членами которого являются все страны Западной Африки, кроме Нигера; Всемирная Торговая Организация (ВТО), членами которой являются все страны Западной Африки, кроме Кабо-Верде и Либерии.

Структура финансовых поступлений в Нигерию такова, что в ней преобладающую долю занимают источники официальной помощи развитию (ОПР) и других официальных потоков [10], которые выступают, главным образом, в виде кредитов, и последние имеют большее значение перед прямыми иностранными инвестициями (ПИИ). Однако в настоящее время наблюдается изменение этих пропорций. Так, в 2019 г. поступления кредитов и ОПР превышали ПИИ примерно в 2 раза, в то время как в 1980-е гг. разница между ними была больше, чем в 5 раз. Кроме того, по темпам ПИИ в Нигерии растут быстрее, чем ОПР. Причем, с 2010 г. в стране наблюдается тенденция устойчивого роста притока ПИИ, в отличие от нестабильных потоков ОПР [11]. То есть ПИИ постепенно набирают больший вес в притоке иностранного капитала по сравнению с ОПР.

Следует отметить, что из всех стран Западной Африки стабильный рост притока ПИИ наблюдается именно в Нигерии, в других странах темпы прироста притока ПИИ отличаются определенными колебаниями, что связано, в основном, с нестабильностью экономической и политической ситуации в этих странах. Притягательными для иностранного капитала в Нигерию выступают именно ее природные ресурсы.

Иностранные инвесторы активно распространяют свое участие в нефтяном секторе. Наряду с относительно благоприятным общим инвестиционным климатом этот сектор их привлекает по двум основным причинам:

1) возможности роста рентабельности, благодаря снижению издержек производства и высокому качеству нигерийской нефти;
2) выгодное географическое положение Нигерии по отношению к главным потребителям, импортерам нигерийской нефти - США, Западной Европе, Индии. Нигерия является вторым поставщиком (после Саудовской Аравии) нефти в США. В США экспортируется около 10\% нефти, добываемой в Нигерии [12].

Наибольший удельный вес иностранных инвестиций идет в нефтяной сектор. Однако Правительство Нигерии пытается направить большую часть инвестиционных вложений инвесторов в газовый сектор, а также ускорить строительство энергетических мощностей, работающих на газе.

Таким образом, Нигерия становится крупнейшим реципиентом прямых иностранных инвестиций в Африке и третьим (после Индонезии и Саудовской Аравии) среди членов ОПЕК.

Заключение. Необходимость активизации процессов интеграции Нигерии в систему мирового хозяйства обусловлена попыткой правительства обеспечить ускорение экономического роста страны. Высокая зависимость экономики Нигерии от поступлений от продажи нефти вызывает необходимость повышения конкурентоспособности нигерийского экспорта.

Для того, чтобы усилить притягательность нефтегазовой промышленности Нигерии для инвесторов как регионального, так и мирового уровня и осознавая способность инвестиций играть чрезвычайно важную роль в достижении экономических целей страны, правительство расширило действующие льготы для частных инвесторов. Однако их уровень еще недостаточно высок и экономическое развитие Нигерии в ближайшее время будет зависеть от результатов переговоров с МВФ, т.е., предоставления финансовой помощи, а также от уровня цен на нефть и газ на мировых рынках.

Таким образом, процесс развития потенциала нефтегазовой отрасли Нигерии сталкивается с проблемами, характерными для большинства развивающиеся стран, располагающими природными богатствами - нефть, газ и прочее, и дальнейшее развитие этого потенциала, а также вовлечение нефтегазового сектора Нигерии в формирующийся мировой нефтегазовый комплекс сопряжено с решением сложного комплекса внутренних задач, изменением конъюнктуры мирового рынка, а также широким развитием отношений с мировыми финансовыми институтами, а значит, геополитическими аспектами экономического роста страны. 


\section{Библиографический список}

1. Environmental policy- and economy - in light of data. Luxembourg: Publications Office of the European Union, 2021. $287 \mathrm{p}$.

2. Balezentis, Tomas Towards carbon free economy and electricity: The puzzle of energy costs, sustainability and security based on willingness to pay // Energy: the international journal. 2021. Volume 214; pp 14-19.

3. Ogbeide-Osaretin, Evelyn Nwamaka Analysing energy consumption and poverty reduction nexus in Nigeria // International journal of sustainable energy. 2021. Volume 40: Number 5; pp 477-493.

4. Nigeria's revenue-raising measures risk exacerbating production declines. GlobalData Energy URL: https://www. offshore-technology.com/author/globaldataenergy/

5. Ayodele, Johnson Oluwole Resource allocation, weaponised poverty, and deviant economies in Nigeria // Journal of contemporary African studies. 2021. Volume 39: Number 2; pp 285-304.

6. Resource governance and protracted conflict in Nigeria's Niger Delta: understanding the perceptions and grievances of the people in oil-bearing communities / John B. Idamkue. Lanham: Lexington Books, 2021. 321 p.

7. Rystad's analysis of African oil and gas projects at risk of FID deferrals (Credit: Rystad Energy) URL: https://www. nsenergybusiness.com/features/oil-investment-africa-coronavirus/attachment/rystad-energy-africa-fids/

8. Nwosa, Philip Ifeakachukwu Oil price, exchange rate and stock market performance during the COVID-19 pandemic: implications for TNCs and FDI inflow in Nigeria // Transnational corporations review. 2021. Volume 13: Number 1; pp 125-137.

9. The business of development in post-colonial Africa / edited by Véronique Dimier, Sarah Stockwell. Basingstoke: Palgrave Macmillan, 2021. $165 \mathrm{p}$.

10. Bloomberg. Tanker tracking data minotored by Bloomberg URL: https://www.bloombergquint.com/markets/ nigeria-in-accord-with-oil-majors-that-may-unlock-new-investment

11. Nigeria: Govt Bows to IOCs, Reverses Deepwater Royalties, Other Taxes in PIB URL: https://allafrica.com/ stories/202104170011.html 